\title{
Scientific school of STANKIN: high-efficiency machining of innovative materials
}

The scientific school of Moscow State University of Technology STANKIN is the leading scientific and educational center of the Russian Federation in the field of science and technology of the machine-building industry and other scienceintensive manufacturing sectors, which introduces traditional and innovative approaches in the educational process for students and experienced specialists, and conducts research activities. The non-interrupted development of the most actual projects related to the critical stages of the modern technical progress in the field of Mechanical Engineering, Material Science, Applied Physics and Mathematics demonstrates the most innovative scientific results, which are published in the high-ranked international scientific journals.

The main principles of scientific school are:

- the intergration of scientific and educational processes, when the most recent results, obtained by pedagogical and academic staff, are brought into the educational process for bachelor, master, and doctoral students; Education conducts for all the pre- and post- educational and academic stages of higher professional education, including post-doctoral school;

- completeness of development, when fundamental and applied research create scientific grounding and technical basis for the subsequent development of new structural solutions from an idea to the competitive and completed engineering product.

One of the most competitive innovative educational and researching team was founded based on the department of High-Efficiency Processing Technologies of Materials (VTO), which includes and collaborates with the most effective and science-intensive laboratories in the Russian Federation and abroad.

The primary goal of VTO is to develop the academic and pedagogical staff, which is ready to take a dare to the most critical research challenges as:

- The creation of new classes of materials with the advanced properties which has no analogs in the modern world;

- Development and research of the coatings for the wide range of modern materials;

- Development of unique technologies and machines, measurement systems, and tools, which has no counterpart, and which can solve the most critical problems of quickly changing and challenging the modern industrial world.

The years of experience and the solid scientific team of highly qualified scientists and specialists make a contribution to the development of innovative products and technologies into the machine-building industry. The most remarkable results of scientific activities in the form of patented technologies, methods, techniques and equipment are commissioned in domestic and foreign engineering enterprises for producing reliable and high-performed products.

The scientific team of VTO was multiply awarded in the most prestigious competitions and exhibitions in the Russian Federation and abroad, national scientific events as winners of grants of the President for the leading scientific schools in the field Engineering and Technical Sciences.

The most recent achievements in the field of high-efficiency machining of innovative materials and advanced manufacturing methods are presented in the current issue of the Journal. 